\title{
ACESSIBILIDADE E INCLUSÃO DE UMA ALUNA COM DEFICIÊNCIA VISUAL NA ESCOLA E NA EDUCAÇÃO FÍSICA
}

\author{
DRA. JANE MÁRCIA MAZZARINO \\ Doutora em Ciências da Comunicação UNISUL e Professora Adjunta do \\ Centro Universitário UNIVATES (Rio Grande do Sul - Brasil) \\ e-mail: janemazzarino@gmail.com \\ DR. ATOS FALKENBACH \\ (in memorian)
}

MS. SIMONE RISSI

Mestre em Ambiente e Desenvolvimento pelo Centro Universitário UNIVATES

e Professora da Rede Pública Municipal de Estrela (Rio Grande do Sul - Brasil)

e-mail: sriss@universo.univates.br

\begin{abstract}
RESUMO
O presente estudo tem como problema de investigação compreender como a escola e as aulas de Educação Física apresentam condições de acessibilidade e de inclusão para uma aluna com deficiência visual na escola comum. O objetivo é investigar o processo de inclusão e de acessibilidade de uma aluna com deficiência visual nas aulas de Educação Física, bem como este processo repercute na aprendizagem e no desenvolvimento da aluna. A metodologia do estudo é de caráter qualitativo, na modalidade do estudo de caso. O estudo conclui que a inclusão de uma aluna com deficiência visual na escola contribui para um aprendizado mútuo entre os alunos, bem como de que a escola e sua comunidade precisam manter-se em contínua qualificação e busca de avanços de conhecimentos nessa área.
\end{abstract}

PALAVRAS-CHAVE: Acessibilidade; inclusão; deficiência visual; escola. 


\section{INTRODUÇÃO}

O presente artigo reflete o tema do ambiente e da acessibilidade na perspectiva de uma aluna do ensino fundamental com deficiência visual na escola comum e nas aulas de Educação Física. Procura-se compreender como uma aluna com deficiência visual se ajusta às condições de inclusão e de acessibilidade nas práticas educativas da escola comum e da Educação Física? Qual a compreensão da aluna com deficiência visual acerca da acessibilidade e da inclusão na escola e nas aulas de Educação Física? De que forma a inclusão e acessibilidade podem contribuir para a aprendizagem de uma aluna com deficiência visual na escola comum?

A inclusão de pessoas com deficiência e alunos sem deficiência surge legalmente no Brasil em 1996 através da Lei de Diretrizes e Bases LDBEN 9394/96, mas foi por meio do movimento Educação para Todos que este movimento teve inicio. En 1945 os países que fundaram a Organização das Nações Unidas para a Educação, a Ciência e a Cultura (Unesco) afirmaram a necessidade do acesso pleno à educação ser assegurado enquanto um direito humano, previsto no artigo 26 da Declaração Universal de Direitos Humanos (UNESCO, $2010 a$ ).

Em 1990, delegados de 155 países e representantes de 150 organizações governamentais e não governamentais participantes da Conferência Mundial sobre a Educação para Todos, reunidos em Jomtien, na Tailandia, aprovaram a Declaração Mundial sobre a Educação para Todos, que reafirma o direito à educação como direito humano fundamental e aponta a necessidade de maiores esforços para atender aqueles que têm necessidades especiais. $\mathrm{Na}$ Conferência definiram-se metas e estratégias para serem alcançadas até o ano 2000, as quais, segundo a Unesco, não foram cumpridas. (UNESCO, 20 I Ob).

Em 1994 o movimento ganhou força com a Declaração de Salamanca sobre Princípios, Política e Práticas na Área das Necessidades Educativas Especiais. O documento reafirma os pressupostos da Declaração Universal dos Direitos do Homem , de 1948, e renova a garantia dada pela comunidade mundial na Conferência Mundial sobre Educação para Todos de 1990. Proclama-se o direito fundamental à educação, a oportunidade de conseguir e manter um nível aceitável de aprendizagem conforme as particularidades de cada educando e de modo a atender a diversidade características e necessidades. No caso daqueles que têm necessidades educativas especiais, procama-se que "devem ter acesso às escolas regulares, que a elas se devem adequar através duma pedagogia centrada na criança, capaz de ir ao encontro destas necessidades" (UNESCO, 20 IOc).

No Brasil, a partir da Lei de Diretrizes e Bases LDBEN 9394/96 a intensificação das práticas de inclusão no Brasil com vistas ao acolhimento da diversidade. 
Para disseminar a política da inclusão foi implantado no Brasil o "Programa Educação Inclusiva: direito à diversidade" pelo Ministério de Educação e Cultura (MEC) em parceria com entidades brasileiras e internacionais e com a Secretaria de Educação Especial (SEESP). Com intuito de expandir o programa para todo o país foram estabelecidos municípios-polo, onde se dá a formação de gestores e educadores inclusivos, que recebem auxílio para que se tornem multiplicadores para outros municípios por meio de seminários regionais (SILVA, 2006).

Quando falamos de inclusão, faz-se necessário pensar em ambientes acessíveis. O movimento da acessibilidade ganha força a partir de 198 | quando as Nações Unidas declararam o Ano Internacional dos Portadores de Deficiência. O Programa da Ação Mundial para Pessoas Portadoras de deficiência foi aprovado em 03 de dezembro de 1982, pela Resolução 37/52 da Assembleia Geral das Nações Unidas, que ressalta o direito das pessoas com deficiência de desfrutarem das melhorias das condições de vidas resultantes do desenvolvimento econômico e social com igualdade como os demais cidadãos (DURAN; PRADO, 2006).

$O$ aprofundamento destas temáticas e suas interfaces requer que se defina o que é deficiência visual segundo a sociedade, a concepção médica e educacional e a acessibilidade na escola.

\section{DEFICIÊNCIA VISUAL: ASPECTOS CONCEITUAIS}

Para quem não é deficiente visual é necessário um deslocamento que deve começar pela compreensão de alguns conceitos iniciais. Segundo Sacks (2006), a ausência de visão na relação com o mundo é para as pessoas com visão um paradoxo entre medo e a confusão. Desde o início da vida criamos correlações entre o mundo de objetos, conceitos e sentidos visuais, já que possuímos a visão em totalidade. Os deficientes visuais possuem uma privação sensorial que é a ausência de visão. Tal privação poderá limitar possibilidades de desenvolvimento e relacionamento com o mundo exterior (AMIRALIAN, 1997). As pessoas com deficiência visual utilizam-se de meios não usuais para estabelecer relações com pessoas e objetos que fazem parte do cotidiano. A ausência da visão também reflete na estruturação do sujeito, tanto nos processos cognitivos como na sua constituição psicológica.

As causas mais frequentes da deficiência visual são congênitas como: retinopatia da prematuridade, corioretinite, catarata congênita, glaucoma congênito, atrofia óptica, degenerações retinianas e deficiência visual cortical. Também podemos destacar as causas adquiridas por doenças como: diabetes; deslocamento de retina, glaucoma, catarata, degeneração senil e traumas oculares (BRASIL, 2005).

O conceito social da deficiência visual está relacionado à imagem de uma pessoa triste, sofrida, sozinha, que vive no escuro, dependente de outra pessoa 
para conseguir se relacionar com objetos e pessoas, como se não fossem capazes de terem uma vida saudável e independente (AMIRALIAN, 1997). Pensar em cegueira é uma questão traumática que perturba com a ideia de que são pessoas que encontram inúmeras dificuldades físicas, motoras, cognitivas e emocionais.

Para além dos conceitos populares de cegueira, os especialistas em educação e os oftalmologistas se voltam para causas e consequências da perda da visão. A imagem visual se constitui numa rede integrada, uma estrutura complexa, sendo os olhos apenas uma parte, pois aspectos fisiológicos, funções sensório-motora, psicológica e perceptiva também fazem parte desse sistema. A capacidade de ver e interpretar as imagens visuais depende da função cerebral de receber, selecionar, decodificar, armazenar e associar imagens e outras experiências anteriores. $\bigcirc$ nervo óptico e a retina são necessários para ver as formas e as cores, sendo que a retina é formada por células foto-receptoras e bastonetes e as células foto-receptoras e os cones são responsáveis pela visão central e visão de cores. Os bastonetes são responsáveis pela visão periférica e adaptação a pouca iluminação. As células nervosas da retina constituem a mácula, ponto central da visão, que tem como função a visão nítida. As terminações dessas células nervosas formam o nervo óptico que transporta o estímulo visual ao cérebro, onde as imagens são interpretadas (BRASIL, 2005).

O conceito médico para cegueira é a medida da capacidade visual das pessoas com deficiência no órgão da visão, sendo a perda total da visão, até a ausência de projeção de luz. Para a Organização Mundial da Saúde (OMS) cego são aqueles sujeitos que apresentam acuidade visual de 0 a 20/200. O mesmo que dizer que enxergam a 20 pés de distância aquilo que um sujeito com sua visão normal enxerga a 200 pés. Há também aqueles que apresentam limitações, mas conseguem realizar afazeres, são denominados como sujeitos com visão residual. Um sujeito considerado com visão residual apresenta acuidade visual de 20/200 pés a 20/70 (AMIRALIAN, I997; BRASIL, 2005).

A deficiência visual é compreendida pela acuidade visual, que também é conceituada legalmente pelo potencial que a pessoa possui para identificar objetos a distância caracterizada pelo ângulo formado por seus olhos. A deficiência visual pode ser conceituada por categorias: a) defeitos ópticos como os problemas de refração do olho: a miopia, o astigmatismo, e a hipermetropia, que podem ser corrigidos através de intervenção cirúrgica, e a ambliopia, que é uma sensibilidade imperfeita da retina, são considerados como primeira categoria; b) a cegueira absoluta, quando o indivíduo é incapaz de detectar algo, e cegueira parcial, quando distingue luz, sombras e contornos são considerados de segunda categoria (GONZÁLEZ; DíAZ, 2007).

Para os educadores o conceito de cegueira, primeiramente, foi definido pela deficiência visual, desde a ausência total de visão, até a perda da projeção de luz e 
não pela acuidade. Até a década de 70 a educação se baseava no diagnóstico do oftalmologista para indicação do método Braille para o ensino, sendo que muitas vezes as crianças acabavam lendo o Braille com os olhos e não com o tato. Isso fez com que o conceito fosse mudado, passando a ser avaliada a maneira de aprendizagem do mundo externo, passando assim ter usado o conceito de deficiente visual para identificar indivíduos que se utilizam do tato para se relacionar com o mundo externo. A visão residual passa a ser usada para aqueles que mesmo com a visão prejudicada; aprendem satisfatoriamente (AMIRALIAN, I997; BRASIL, 2005).

\section{MÉTODO}

O estudo trata sobre a participação de uma menina com deficiência visual matriculada no sexto ano do ensino fundamental da escola comum de uma cidade do interior do Rio Grande do Sul, onde se analisam os conteúdos da acessibilidade e da inclusão em aulas de Educação Física. A modalidade do estudo é qualitativa na forma de um estudo de caso.

A menina com deficiência visual possui diagnóstico de retinopatia da prematuridade ou fibroplasia retotental. A retinopatia da prematuridade pode ser decorrente de imaturidade da retina, causada pela baixa idade gestacional e/ou pelo excesso de oxigênio na incubadora. $\bigcirc$ oxigênio em alta concentração provoca vasoconstrição e que impede a irrigação da retina provocando pregas retinianas, massa fibrosa ou cicatricial, retração da retina, ou deslocamento total ou parcial. No deslocamento de retina os processos cirúrgicos têm pouco sucesso. Muitas vezes é preferível a estimulação da visão residual remanescente ou a utilização de óculos, lentes para miopia, lentes de aumento manual, lupas e outros (BRASIL, 2005).

$\mathrm{Na}$ coleta de informações fizemos uso das observações e entrevistas. As observações foram desenvolvidas com pautas voltadas para a acessibilidade na escola e a inclusão da menina nas aulas de Educação Física. As observações foram realizadas no período de março até julho 2009. Foram realizadas 8 (oito) observações e as pautas foram: a) o acesso da aluna à escola; b) as relações com colegas e professores; e c) o acesso para as aulas de Educação Física.

Também foram realizadas 4 (quatro) entrevistas: uma com a professora de Educação Física, uma com a professora de Português, uma com a diretora da escola e uma com a aluna deficiente visual As entrevistas com as professoras levantaram dados sobre formação, experiência como professor e na interação com alunos com deficiência, capacitação, percepções sobre a inclusão de alunos com deficiência, dificuldades e facilidades, percepções sobre a participação da aluna com deficiência visual na escola e avaliação das condições de acessibilidade da escola. 
Com a aluna buscou-se investigar como ela se sentia na escola e nas aulas, especialmente de Educação Física, sua relação com colegas, percepções sobre o ambiente da escola para se locomover, atividades preferidas, sensações e necessidades, de modo a compreender as condições de acessibilidade na escola, conforme percebidas pela aluna.

Os dados coletados permitiram a organização das categorias de análise que seguem: a) acessibilidade à escola; b) as relações com professores e colegas; c) acessibilidade às aulas de educação física.'

\section{ACESSIBILIDADE NA ESCOLA}

A acessibilidade para alunos com deficiências nas escolas é sempre um ponto frágil. Estudos demonstram que as escolas começam a preocupar em relação em direção à inclusão e à acessibilidade quando os alunos com deficiências quando estes começam a ingressar no ambiente escolar (FALKENBACH et al., 2008a; FALKENBACH et al., 2008b, FALKENBACH et al., 2008c; SANTOS; FALKENBA$\mathrm{CH}, 2008)$. Tal postura denuncia o despreparo e a falta de organização prévia no sentido pedagógico e estrutural.

As Leis Federais 10.048/2000 e 10.098/2000 e o Decreto Federal 5.296/2004 garantem a acessibilidade para todas as pessoas. Elas tratam do direito de ir e vir com total autonomia mediante a eliminação das barreiras físicas das edificações, dos espaços públicos, dos meios de transporte, das sinalizações e das comunicações para as pessoas com deficiência ou mobilidade reduzida. As leis deixam claro que qualquer obstáculo que impeça ou limite o acesso, a liberdade de movimento, a circulação com segurança são denominados de barreiras arquitetônicas. Elas são classificadas em:

a) barreiras urbanísticas: que são as existentes nas vias e espaços de uso público;

b) barreiras nas edificações: são as existentes interna ou externamente nas edificações públicas e coletivas, nas edificações de uso privado, multifamiliar e nos seus entornos;

c) barreiras nos transportes: existentes nos serviços de transportes;

d) barreiras de comunicações e informações: qualquer obstáculo que dificulte a expressão ou o recebimento de mensagem por intermédio dos meios de comunicação, bem como os que empeçam ou dificulte o acesso à informação.

I. O estudo foi aprovado pelo Comitê de Ética em Pesquisa da UNIVATES por estar adequado às normas previstas na Resolução CNS 196/96. 
Conforme as leis, as escolas também necessitam estar preparadas para que possam receber todos os tipos de alunos, pois o Decreto Federal 5.296, de 2 de dezembro de 2004 define prazos para a garantia de acessibilidade, sob pena da não autorização para o funcionamento (DURAN; PRADO, 2006).

Muitas vezes o ato de incluir o aluno com deficiência leva em conta o acesso e a disponibilidade de espaços físicos adequados para receber as pessoas com necessidades educacionais especiais. Acessibilidade é um aspecto de inclusão.

Segundo Duran e Prado (2006), as condições de acesso se aplicam a todos os estabelecimentos de ensino de qualquer nível, modalidades ou etapas, públicos ou privados. A acessibilidade deve ser garantida a todos os ambientes da escola, salas de aulas, laboratórios de informática, salas de aulas práticas, bibliotecas, sala dos professores, secretarias, coordenação, as áreas esportivas, refeitório, sanitários, o pátio, enfim todo o ambiente escolar. Para o deficiente visual deverá haver a sinalização e a comunicação abrangente em todos os prédios, com letras em Braille e também com símbolos para facilitar a compreensão de todos. Para os alunos com deficiência visual deverá haver o piso tátil de alerta junto a escadas, rampas e ao mobiliário quando esses apresentarem obstáculos e saliências. As portas deverão ser de cores contrastantes com o piso e as paredes. Os pilares deverão ser isolados em locais de pouco fluxo de pessoas. Os sanitários acessíveis por pavimento devem possuir barras de apoio e lavatório no mesmo ambiente. As escolas devem disponibilizar mobiliário, equipamentos e dispositivos de ajuda técnica que permitam o acesso para as atividades escolares. $\bigcirc$ transporte coletivo também deve estar acessível a todos para que possa incluir e prestar serviço às pessoas com necessidades especiais.

A familiarização com o ambiente escolar é muito importante para os alunos com necessidades especiais. Para os alunos com deficiência visual essa familiarização deve ser feita da sua casa até a escola. Também é muito importante, no primeiro momento, que o aluno conheça o ambiente escolar com o auxílio de uma pessoa que o conduza. Após essa familiarização é preciso que as coisas fiquem sempre no mesmo local e quando algo for mudado o aluno com deficiência seja avisado (DURAN; PRADO, 2006).

\section{ACESSIBILIDADE DA ALUNA COM DEFICIÊNCIA VISUAL NA ESCOLA}

A partir das falas dos informantes coletadas por meio de entrevistas, identificamos que a escola procura organizar-se para bem receber a menina com deficiência visual. A menina possui uma irmã que estuda na mesma escola e o deslocamento da menina é, assim, facilitado pela irmã, que a guia até a sala de aula.

Observamos que na sala de aula a menina costuma ficar na porta. Os colegas chegam e a cumprimentam falando ou conversando. Ao dar o sinal para o início 
das aulas ela é levada por um colega para a sua classe, que fica em frente à mesa da professora. A professora relata que os trabalhos em braile são escritos e desenvolvidos em outra escola para ela (Observação número I em março 2009).

Segundo os entrevistados, todas as conduções da menina com deficiência visual na escola são realizadas com o auxílio de um colega que funciona como guia da turma. Há situações em que o próprio professor é seu guia e a conduz para as atividades ou locais em que será desenvolvida.

No entanto, a escola apresenta algumas dificuldades relativas a barreiras arquitetônicas, conforme as falas apontaram:

"A questão da acessibilidade na nossa escola é um pouco complicado pela questão das escadas, para ela ir no refeitório, para o recreio, para a Educação Física, enfim é complicado, pois as escadas acabam dificultando a locomoção dela sozinha" ${ }^{2}$ (Entrevista com a diretora em outubro de 2008).

“Uhm... ah! O difícil é que de vez em quando eu, eu me atrapalho, né, nuns negócios aí, às vezes, eu me atrapalho, eu acho que tô indo pra um lado e tô indo pro outro, aí eu tenho que me achar assim, né, e fácil, é que é tudo muito grande, não tem tantas coisas que me atrapalham assim. Ah, às vezes, tem uma parede, uma flor que eu despedaço tudo (risos)" (Entrevista com a aluna em abril de 2009).

Estas dificuldades tendem a ser enfrentadas com ajuda de colegas e professores. Vygotsky (1997) explica que a relação com as pessoas com deficiências é sempre especial. De fato as relações do professor para atuar com a menina é destacada em relação aos demais alunos, fato que reflete a preocupação e sentimento do professor em ajudar e orientar a menina.

Foi comum observar os colegas cumprimentando-a pelo nome. Também percebemos que ela responde e identifica aqueles que cumprimentam. Há aqueles que não cumprimentam porque passam rapidamente e seguem para seus afazeres. Tal atitude demonstra que a menina está incorporada ao grupo, que também não estranha sua presença.

Apesar de grande parte de suas comunicações se dirigirem para a professora, principalmente em situações de auxílio pedagógico, foi possível observar colegas desejando auxiliar ou respondendo para ela antes da professora.

A naturalização do grupo com a menina com deficiência visual é um importante aspecto que faz referência ao avanço cultural das crianças que são alunas do grupo. A compreensão de Vygotsky ( 1997 ) acerca da relação social e das influências

2. As descrições das citações respeitam a forma original de comunicação desenvolvida durante as entrevistas. As descrições não sofreram modificações por parte da pesquisadora. 
para a aprendizagem ajuda a entender o processo de relações do grupo das crianças, uma vez que as mesmas reconhecem a menina com deficiência visual integrante do grupo, organizam formas de estabelecer comunicação, de serem reconhecidas e de auxiliar a colega em suas necessidades.

\section{A RELAÇÃO COM OS PROFESSORES E COLEGAS AUXILIANDO NA APRENDIZAGEM E NO DESENVOLVIMENTO}

Quando avaliamos o desenvolvimento de uma criança buscamos observar quais atividades ela consegue desempenhar sozinha. Observamos o seu dia a dia para conseguirmos perceber quais tarefas ela realiza. Para Vygotsky ( 1998), a capacidade que a criança apresenta para desenvolver sua atividade sozinha denomina-se o nível de desenvolvimento real, que são etapas já alcançadas por ela. Essas são etapas do processo de desenvolvimento já completadas.

O autor pede atenção para que no processo de compreensão do desenvolvimento de uma criança, seja considerado não apenas o nível de desenvolvimento real, mas também o nível de desenvolvimento potencial, que é a capacidade da criança realizar atividades com o auxílio de uma pessoa mais experiente do que ela.

Na teoria de Vygotsky, é fundamental observarmos o desempenho da criança quando realiza uma tarefa com interferência de outra pessoa. No momento do desenvolvimento, não é qualquer indivíduo que realiza uma atividade apenas com ajuda de outro. $O$ desenvolvimento potencial não é caracterizado apenas por etapas já alcançadas, mas por etapas posteriores, sendo que a interferência de outras pessoas é fundamental para o resultado da sua ação individual. A partir dessa teoria, interação social passa a ser fundamental para o processo de construção das funções psicológicas do ser humano. $\bigcirc$ ambiente social e as relações com o outro, são fundamentais para o processo de construção do ser psicológico individual.

A partir dos conceitos de desenvolvimento real e potencial é que Vygotsky define a zona de desenvolvimento proximal, que é a distância entre o nível de desenvolvimento real e o nível de desenvolvimento potencial, ou seja, o que a criança realiza sozinha e o que ela pode vir a realizar com a ajuda de outra pessoa mais experiente do que ela.

Segundo o autor a aprendizagem precede o desenvolvimento. Já as habilidades, não precedem o conhecimento, mas é no processo de elaboração dos conhecimentos que se constroem as habilidades. $\bigcirc$ aprendizado desperta processo de desenvolvimento, que são mudanças qualitativas que irão fazer parte das funções psicológicas do indivíduo.

Para tanto, podemos perceber a importância do ambiente sociocultural na formação das funções psicológicas da criança. É a relação do indivíduo com 
O ambiente que estabelece forte ligação entre o processo de desenvolvimento e aprendizado. Na zona de desenvolvimento proximal a interferência de outras pessoas é transformadora.

aprendizado impulsiona o desenvolvimento segundo a teoria da zona de desenvolvimento proximal. A escola tem um papel essencial para a formação psicológica.

O professor é visto como o mediador, facilitador entre o que a criança já sabe e o que ela possa vir a saber. Para que essa mediação ocorra é importante que ele conheça o nível de desenvolvimento real do seu aluno, que é ponto de partida para atingir novos níveis de desenvolvimento.

Tal referencial é de suma importância em se tratando da inclusão e da acessibilidade de alunos com deficiência visual na escola. Desta forma o ambiente escolar age sobre a criança possibilitando-lhe aprendizados e condições para sua interação e diálogo. Nesse caso o ambiente escolar é um elemento potencializador da aquisição da cultura da criança e de suas relações interpessoais. Para Vygotsky um ensino com qualidade é aquele que adianta ao desenvolvimento.

No presente estudo, podemos perceber através das observações realizadas nas aulas e das entrevistas que os professores e os colegas têm um papel importante no aprendizado da aluna, sendo nesse caso um potencializador cultural conforme Vygotsky trata na teoria do desenvolvimento proximal.

A aluna relata que suas colegas a conduzem durante uma aula: "Tive uma Educação Física onde eu fiz alongamento, pulei corda, caminhei com minhas colegas G. e T". (Memorial descritivo $n^{\circ}$ I, de junho de 2009). Noutra fala a aluna relata como percebe a ajuda dos colegas: "Percebo que eles são meus amigos, que eles me ajudam, até porque às vezes tem coisas que eles querem aprender comigo pra eles poderem me ajudar " (Entrevista com a aluna em outubro de 2009). As observações comprovam a fala da menina.

09h25min- Estão sentadas conversando. A professora vem até elas, fala. Em seguida elas levantam e vão fazer os exercícios que a professora pede. B. está pulando em um pé e em seguida com os dois. Pula sobre o pé direito, depois sobre o esquerdo. Sorri e faz. Faz polichinelo, sorri durante o exercício. A professora pega nos braços dela e diz como é para ela fazer o exercício. Pede para B. pular alternando braços e pernas, começa, sorri e diz: - "ai sora eu não sei." Tenta novamente. (observação número 6 de junho de 2009).

Percebemos que tanto a professora com os colegas estão atentos à aluna e auxiliam-na no que necessita para acompanhar as atividades desenvolvidas nas aulas. 


\section{ACESSIBILIDADE ÀS AULAS DE EDUCAÇÃO FÍSICA}

Antes de apresentar as reflexões acerca do conteúdo da coleta de informações que permitiu organizar a categoria da acessibilidade nas aulas de Educação Física para a menina com deficiência visual, é relevante destacar que o tema da acessibilidade não é comum em se tratando das práticas educativas da Educação Física. O histórico da Educação Física voltado para o rendimento, a técnica e a seleção sempre destacou quem pode e quem não pode fazer a Educação Física, seja através das dispensas históricas da Educação Física, seja através da desinformação ou caráter seletivo e excludente das aulas (FALKENBACH, 2002; SANTIN, 200 I).

Foi a partir dessa cultura da Educação Física que começamos a pensar o tema da acessibilidade e da inclusão nas aulas de Educação Física com alunos com deficiência visual. No presente estudo foi possível destacar aspectos interessantes da acessibilidade da menina com deficiência visual na prática da Educação Física em relação a: a) o acesso e os materiais; b) a participação nas atividades; c) as dificuldades enfrentadas.

Em relação ao acesso da menina nas aulas de Educação Física os dados levantados, por observação e por entrevistas, apontam que a condução dela é realizada com apoio dos colegas da turma. Foi possível perceber que um colega sempre se prontifica para conduzíla à quadra coberta da escola. Ao receber o sinal de que é Educação Física ela levanta e espera ao lado de sua classe, um colega logo chega lhe alcança o braço para ser guiada. Ela sempre é conduzida à frente do grupo. Ao chegar na quadra coberta, ela senta em um banco e aguarda a chegada dos demais. Em todo o desenvolvimento da aula foi possível perceber a atenção destacada da professora e dos colegas com ela, sempre no sentido de ajudar a cumprir com as atividades que são adaptadas para sua condição (Observação número 4 de março de 2009).

Conforme Vygotsky (1997) as relações com a criança com deficiência vão ser sempre especiais. Apesar de haver um cuidado e uma relação de inclusão da menina no grupo, ainda é perceptível a relação especial que é dedicada a ela e se diferencia do tratamento dado aos demais colegas da turma, seja pela professora ou pelos colegas. Conforme Falkenbach (2003) será a atitude do professor que poderá auxiliar na aprendizagem da inclusão pelos colegas do grupo também.

A observação e as entrevistas desenvolvidas na escola revela que há uma preocupação dos professores em criar a acessibilidade para participação nas aulas. Percebemos que há carência de materiais específicos para a deficiência visual, o que se comprova na fala da professora:

"A dificuldade que avalio que exista é a falta de material, a escola poderia ter aquelas bolas com guiso, materiais específicos para cegos. Por que preciso adaptar tudo conforme o que 
possuímos na escola, o material é a maior dificuldade que possuímos" (Entrevista com a professora de educação física em abril de 2009).

Percebemos que a menina possui um bom acesso com relativa autonomia na escola e nas aulas de Educação Física. $O$ ato de descer escadas, guiar-se e situarse nos locais identificando-os ocorrem porque ela possui um período de tempo significativo na escola exercitando sua orientação.

As observações realizadas nas aulas de Educação Física demonstraram que a menina possui uma desenvoltura positiva nas atividades práticas da aula. Melo (2004) explica que as aulas de Educação Física precisam desenvolver as potencialidades de alunos com deficiência visual assim como são estimuladas em alunos sem deficiência.

Mesmo quando outros colegas realizam outras atividades a menina possui atividades próprias para realizar. Durante as observações foi possível perceber satisfação no comportamento da menina que sorria e interagia com colegas a todo o tempo.

A observação que segue apresenta uma passagem das atividades realizadas pela menina:

"9h20min A turma realiza atividades de trilhar cordas. A menina pula em um pé só. Primeiro com a perna esquerda e depois com a direita sem a corda. A professora busca a corda de trilhar para a menina pular. Uma aluna ajuda a professora a segurar e trilhar a corda. A menina pula sempre que a professora dá o sinal falando para ela pular. Consegue pular a corda durante seis repetições sem errar" (Observação número 5 de abril de 2009).

É importante compreender como o contexto educativo desenvolvido nas aulas de Educação Física, apesar das dificuldades apontadas pela professora, consegue promover aprendizagens na menina com deficiência visual. Tal realidade está em acordo com os pressupostos de Vygotsky (1997) para quem a deficiência é muito mais social que biológica, sendo as limitações e fragilidades impressas pelo contexto social. Um contexto social que provoca e estimula consegue naturalizar e desenvolver aprendizagens que rompem com a ideia de deficiência.

\section{CONSIDERAÇÕES FINAIS}

O estudo aponta que o ambiente escolar pode atuar como um espaço de acessibilidade e de inclusão na escola comum. Foi interessante perceber como o contexto sociocultural desempenha a aprendizagem de processos de desenvolvimento em alunos com deficiência visual. A descrição das realidades observadas e as falas dos participantes do estudo, coletadas por meio das entrevistas, contribuíram para refletir acerca das influências do meio sobre as aprendizagens individuais, bem 
como das repercussões culturais da presença de uma aluna com deficiência visual no grupo de estudantes e na escola.

Voltando aos objetivos do estudo foi possível destacar que:

a) A menina com deficiência visual possui um bom acesso à escola que não possui uma ideal acessibilidade, mas a vivência de longo prazo da menina na escola permite que ela desempenhe bons níveis de autonomia no seu deslocamento pela mesma;

b) A relação com os colegas e professores em sala de aula e aulas de Educação Física é positiva e com repercussões culturais sobre o grupo e sobre os professores, que se organizam para incluir a menina com deficiência visual;

c) Ao mesmo tempo em que existe essa organização, também é possível perceber que as relações com o grupo e dos professores com a menina está naturalizada, incorporando-se ao cotidiano da escola;

d) Apesar da Educação Física não contar com as condições ideais para a inclusão e participação de alunos com deficiência visual, foi possível constatar o movimento inclusivo nas aulas de Educação Física de modo a promover a adequação de atividades para a participação da menina;

e) A menina demonstrou gostar das aulas de Educação Física e sente-se incluída e participante, apresentando boas habilidades com atividades complexas para uma pessoa com deficiência visual.

Os dados apontam que a aluna com deficiência visual sente-se incluída na escola e nas aulas de Educação Física, mesmo que as condições arquitetônicas de acessibilidade não sejam as ideais. As dificuldades são revertidas em comportamentos solidários de alunos e professores para com a aluna com deficiência visual. $\bigcirc$ estudo evidencia que a inclusão do deficiente visual no ambiente escolar e nas aulas de Educação Física promove um aprendizado mútuo entre os alunos sem deficiência, a aluna deficiente e professores, provocando a reorganização das atividades pedagógicas, o que se refletiu, ainda, na inclusão dos deficientes na realidade vivida por eles, permitindo maior respeito às diferenças de cada um.

Neste sentido, o processo de inclusão contribui para a aquisição de novos conhecimentos não só por parte da aluna com deficiência visual, mas também de seus colegas, professores e funcionários da escola. A amizade e o carinho que todos apresentam com a aluna fazem com que ela se sinta bem no ambiente escolar, acolhida e participante da turma e da escola como um todo. 


\section{Accessibility and inclusion of a pupil with visual deficiency in the school and the physical education}

ABSTRACT: The present study is to research problem to understand how the school and physical education classes present conditions of accessibility and inclusion for a student with visual impairments in regular schools? The goal is to investigate the process of inclusion and accessibility for a student with visual impairments in physical education classes and how this process affects learning and student development. The methodology of the study is qualitative, in the form of case study. The study concludes that the inclusion of a student with visual impairment in school contributes to mutual learning among students and that school and your community need to remain in constant search of qualification and progress of knowledge in this area.

KEY WORDS: Accessibility; inclusion; visual deficiency; school.

\section{Accesibilidad y inclusion de una pupila con deficiencia visual en la escuela y la educación física}

RESUMEN: El actual estudio tiene como problema de investigación entender como la escuela y las lecciones de la educación física presentan condiciones de la accesibilidad y de la inclusión para una pupila con deficiencia visual en la escuela común. El objetivo es investigar el proceso de la inclusión y de la accesibilidad de una pupila con deficiencia visual en las lecciones de la educación física, tan bien como este proceso él rees-eco en aprender y el desarrollo de la pupila. La metodología del estudio es de carácter cualitativo, en la modalidad del estudio de caso. El estudio concluye que la inclusión de una pupila con deficiencia visual en la escuela contribuye para aprender mutuo entre las pupilas, así como ésa la escuela y su necesidad de la comunidad de permanecer en la calificación y la búsqueda continua de avances del conocimiento en esta área.

PALABRAS CLAVE: Accesibilidad; la inclusión; la deficiencia; visual.

\section{REFERÊNCIAS}

AMIRALIAN, M. L. T. M. Compreendendo o cego: uma visão psicanalítica da cegueira por meio de desenho-estórias: São Paulo: Casa do Psicólogo, 1997.

BRASIL. Lei n 10.048, de 8 de novembro de 2000a. Dá prioridade de atendimento às pessoas que especifica, e dá outras providências. Diário Oficial [da] União, Brasília, 9 nov. 2000. Ano CXXXVIII No 2 16-E. Disponível em: <http://www6.senado.gov.br/legislacao/ ListaPublicacoes.action?id=230970>. Acesso em: 30 ago. 2010.

BRASIL. Lei n 10.098, de 19 de dezembro de 2000b. Estabelece normas gerais e critérios básicos para a promoção da acessibilidade das pessoas portadoras de deficiência ou com mobilidade reduzida, e dá outras providências. Diário Oficial [da] União, Brasília, 19 dez. 2000. Ano CXXXVIII No 244-E. Disponível em: <http://www6.senado.gov.br/legislacao/ ListaTextolntegral.action?id=218628>. Acesso em: 30 ago. 2010. 
BRASIL. Decreto n 5.296, de 2 de dezembro de 2004. Regulamenta as Leis nos 10.048, de 8 de novembro de 2000, que dá prioridade de atendimento às pessoas que especifica, e 10.098, de 19 de dezembro de 2000, que estabelece normas gerais e critérios básicos para a promoção da acessibilidade das pessoas portadoras de deficiência ou com mobilidade reduzida, e dá outras providências. Diário Oficial [da] União, Brasilia, 2 dez. 2004. Seção I , p. 2. Disponível em: <http://mww. planalto.gov.br/ccivil/_ato2004-2006/2004/decreto/d5296.htm>. Acesso em: 30 ago. 2010.

BRASIL. Lei no 9.394, de 20 de dezembro de 1996. Estabelece as diretrizes e bases da educação nacional. Diário Oficial [da] União, Brasília, 23 dez. 1996. Seção I , p. 27833. Disponível em: <http://www.planalto.gov.br/ccivil_03/Leis/L9394.htm>. Acesso em: 30 ago. 2010.

BRASIL, MINISTÉRIO DA EDUCAÇÃO. Secretaria de Educação Especial. Saberes e práticas da inclusão: desenvolvendo competências para o atendimento às necessidades educacionais especiais de alunos cegos e de alunos com baixa visão. Brasília, 2005.

DURAN, M. G.; PRADO, A. R. A. Acessibilidade nos estabelecimentos de ensino. In. III SEMINÁRIO NACIONAL DE FORMAÇÃO DE GESTORES E EDUCADORES - EDUCAÇÃO INCLUSIVA: DIREITO A DIVERSIDADE. ENSAIOS PEDAGÓGICOS. Brasília. Anais... Brasília: Ministério da Educação, 2006. v. I, p. I37-| 42.

FALKENBACH, A. P. Um estudo de casos: as relações de criança com síndrome de Down e de crianças com deficiência auditiva na psicomotricidade relacional. 2003. 452p. Tese (Doutorado) Programa de Pós Graduação Ciências do Movimento Humano, UFRGS, Porto Alegre, 2003.

FALKENBACH, A. P.; MACHADO, G.; ORDOBAS, A. C. M. Experiências de inclusão de professores da educação física na escola comum: a relação professor/aluno com necessidades especiais. Lecturas Educación Física y Deportes, Buenos Aires, v. 10, p. I - 13, nov., 2008.

FALKENBACH, A. P.; et al. Panorama da inclusão de alunos com necessidades especiais na escola. Lecturas Educación Física y Deportes, Buenos Aires, v. 13, p. I-8, dez., 2008a.

FALKENBACH, A. P. et al. A formação e a prática vivenciada dos professores de educação física com a inclusão de crianças com necessidades educacionais especiais na escola comum. Temas sobre Desenvolvimento, São Paulo, v. 16, p. 56-60, maio, 2008b.

GONZÁLEZ, M. P.; DÍAZ, J. M. Deficiência visual: aspectos evolutivos e educacionais. In: GONZÁlEZ, E. (Org.). Necessidades educacionais específicas. Porto Alegre: Artmed, 2007.

MELO, J. P. O ensino da Educação Física para deficientes visuais. Revista Brasileira de Ciências do Esporte, Campinas, v. 25, n. 3, maio/2004. p. 117-132.

ORGANIZAÇÃO DAS NAÇÕES UNIDAS PARAA EDUCAÇÃO, A CIÊNCIA E A CULTURA. Diez aspectos de la Educación para Todos. Disponível em: <http://www.unesco.org/es/ efa/the-efa-movement/l 0-things-to-know-about-efa/>. Acesso em: 30 ago. 2010.

ORGANIZAÇÃO DAS NAÇÕES UNIDAS PARAA EDUCAÇÃO, A CIÊNCIA E A CULTURA. Conferencia Mundial sobre la EPT. Jomtien, 1990. Disponível em: < http://www.unesco.org/es/ efa/the-efa-movement/world-conference-on-efa-jomtien- 1990/>. Acesso em: 30 ago. 2010.

ORGANIZAÇÃO DAS NAÇÕES UNIDAS PARA A EDUCAÇÃO, A CIÊNCIA E A CULTURA. Declaração de Salamanca sobre Princípios, Política e Práticas na Área das 
Necessidades Educativas Especiais. Salamanca, 1994. Disponível em: <http://unesdoc. unesco.org/images/00 13/001393/I39394por.pdf.>. Acesso em: 30 ago. 2010.

ORGANIZAÇÃO DAS NAÇÕES UNIDAS. Resolução Programa de Ação Mundial para as Pessoas com Deficiência. 1982. Disponível em: <http://www.mp.mg.gov.br/portal/public/ interno/repositorio/id/6494>. Acesso em: 28 de jun. 201 I.

SACKS, O. Um antropólogo em Marte: sete histórias paradoxais. São Paulo: Companhia das Letras, 2006.

SANTIN, S. Educação Física: da alegria do lúdico à opressão do rendimento. Porto Alegre: EST, $200 \mathrm{I}$.

SANTOS, H. G. dos; FALKENBACH, A. P. Aprendizagem e desenvolvimento da criança com deficiência visual: os processos compensatórios de Vygotski. Lecturas Educación Física y Deportes, Buenos Aires, v. 122, p. I-7, jul., 2008.

SILVA, C. M. D. Inclusão: dos limites às possibilidades. In. ROTH, B. W. (Org.) Experiências educacionais inclusivas: Programa Educação Inclusiva: direito à diversidade. Brasília: Ministério da educação, Secretaria de Educação Especial, 2006.

UNESCO. Diez aspectos de la Educación para Todos. Disponível em http://mww.unesco.org/es/ efa/the-efa-movement/I 0-things-to-know-about-efa/ Acesso em: 30 de agosto de 20 I 0b.

VYGOTSKY, L. S. Obras escogidas: fundamentos de defectología. Madrid: Visor, 1997. A formação social da mente. São Paulo: Martins Fontes, 1998.

Recebido: 23 set. 2009

Aprovado: 30 set. 2010

Endereço para correspondência: Jane Márcia Mazzarino Av. Avelino Talini, |7| - Bairro Universitário, Lajeado - RS CEP: $95900-000$ 